\title{
KINTSUGI: REFAZER O FINNEGANS WAKE
}

\section{KINTSUGI: REMAKING FINNEGANS WAKE}

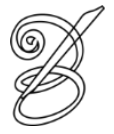 \\ Caetano Waldrigues GALINDO* \\ Universidade Federal do Paraná \\ Curitiba, Paraná, Brasil
}

Resumo: Este artigo é na verdade uma carta de intenções; uma breve análise da situação tradutória específica do último romance de Joyce, seguida de uma proposta singular de projeto de tradução, tanto mais singular por estar de fato embasando um trabalho em curso de tradução integral da obra, aqui exemplificada por uma amostra. Palavras-chave: James Joyce. Finnegans Wake. Tradução Literária. Recriação. Kintsugi.

Abstract: This paper, as a matter of fact, is a letter of intentions; a brief analysis of the specific problems involved in the translation of James Joyce's last novel, followed by a singular proposition of a translation project, all the more singular for being in actual use as the basis for a work-in-progress translation of the entire novel, of which a sample appears here.

Keywords: James Joyce. Finnegans Wake. Literary Translation. Recreation. Kintsugi.

RECEBIDO EM: 27 de setembro de 2019

ACEITO EM: 25 de novembro 2019

PUBLICADO EM: março 2020 
Finnegans Wake é um livro que desestabiliza o próprio processo de leitura, por se basear numa espécie de explosão do princípio do trocadilho multilíngue, que gera um texto que, mais do que dizer univocamente alguma coisa, prefere apontar em muitas direções, prefere insinuar várias possibilidades latentes. Em sendo assim, é claro que o livro representa também um desafio para a tradução. Se é impossível "ler" o Wake segundo os mesmos critérios que empregamos para outras obras literárias, traduzi-lo também implica a dedução (ou mesmo a "criação") de uma série própria de critérios novos, que permitam que cada projeto estabeleça suas condições de sucesso, suas balizas, seus alvos.

Há uma tradução completa do Wake em português, o Finnícius Revém, de Donaldo Schüler, publicado pela Ateliê Editorial. Há também diversos fragmentos, entre os quais se destaca o volume Panaroma do Finnegans Wake, dos irmãos Augusto e Haroldo de Campos. Neste momento, um coletivo de tradutores organizados em torno da pesquisadora Dirce Waltrick do Amarante prepara também uma nova versão integral.

O que difere o meu projeto (também uma tradução completa) é uma abordagem que vem sendo testada repetidamente, e que explica também mais essa tentativa (incluída no final do artigo) de tratar as famosas linhas que concluem o romance. Penso numa espécie de tradução “performance", em que ao invés de sondar as anotações e possibilidades infinitas de cada evento polissêmico do romance, eu na verdade tento traduzir sem apoio, sem bibliografia (contando, é claro, com mais de quinze anos de estudo do livro), mirando integralmente na beleza, nos efeitos sonoros, no impacto do texto. É um ensaio. É um estudo ainda. É dançar sobre o texto, aceitar a mão que Joyce estendeu.

Vale lembrar que ele mesmo, nas duas ocasiões em que esteve envolvido com projetos de tradução de trechos do Wake para o italiano e o francês, endossou esse tipo de "liberdade" que abria novas portas em cada novo idioma.

Dessa maneira, o que se pretende numa tradução como essa não seria, para emprestar uma metáfora cansada, a construção de um novo invólucro que desse conta do mesmo “conteúdo" do original, e nem mesmo a reconstrução inconsútil daquele invólucro original.

Se em muitas ocasiões já tive oportunidade de discordar da formulação de Eco, da ideia da tradução literária como algo que produz um "quase”, um simulacro; se já pude argumentar bem mais de uma vez em favor de uma leitura que acompanhe mais de perto o que Paulo Henriques Britto sempre repete, que a tradução precisa fornecer um texto que permita a um leitor que acesse apenas aquele texto dizer, sem mentir, que leu o original: ou seja, num sentido muito forte, um texto que é "a mesma coisa" que o original; se defendi e defendo essas ideias no que se refere à tradução literária como um todo, tenho no entanto que abrir uma exceção 
para o Finnegans Wake. E isso, afinal, é precisamente o que tende a acontecer com qualquer tipo de linha investigativa que se debruce sobre o Wake: ela precisará rever seus princípios mais caros e mais estáveis para dar conta dessa realidade algo inapreensível, tantalizante.

Não busco agora jarros novos, nem réplicas. O que procuro obter é em certa medida equivalente ao resultado da operação japonesa chamada de kintsugi, o reparo de objetos partidos em que não se busca ocultar as emendas mas, pelo contrário, tenta-se realçá-las com o uso de metais preciosos, transformando a "cicatriz" em distinção, fazendo da quebra e de sua refacção uma parte integral de um objeto novo, não menos, mas mais precioso.

O Finnegans Wake que deve emergir dessa empreitada guardará com seu original uma relação diferente daquela que caracteriza todas as minhas outras traduções. Ele será mais confessadamente uma tradução, mais tematizadamente uma tradução, mais declaradamente meu, e menos "transparente".

Isso há de acarretar a necessidade de abrir mão de certas leituras e, mais complicado ainda (se considerado daquele meu ponto de vista mais "tradicional") a necessidade de determinar um "meu" ponto de vista, conquanto plurissêmico, para cada trecho e cada palavra. Para atingir algo que equivalha à granularidade do original, será necessário aceitar o acaso, abrir-se ao novo, aceitar o processo de tradução como processo, como evento, como performance, como singularidade destacada em considerável medida do original, que lhe serve como estabelecedor de balizas, sim, e de parâmetros, especialmente balizas e parâmetros negativos. Sabemos, afinal, com alguma segurança o que o Finnegans Wakenão é, e podemos determinar com bastante certeza o que suas frases não querem dizer. E essa maneira, digamos, apofática de se tentar estabelecer o que de fato é o Wake, pode, acredito, gerar uma nova maneira de se chegar à estabilidade da relação original-tradução, não mais buscando a coextensibilidade das definições (e semioses) positivas, mas tentando garantir a biunivocidade das determinações negativas centrais.

É claro que, ao aceitar o elemento do acaso, do momento, e da performance, há que se também ampliar as possibilidades de referência do original. A chave, contudo, é tentar manter suficiente lastro na simetria das negatividades para que os acréscimos eventuais não a descaracterizem.

Tentemos.

*

O trecho apresentado (pp 626-628) é a conclusão do livro, onde Anna Livia, a personagem feminina principal, desiste da vida, foge de casa, abandona a vida inteira enquanto, identificada 
como sempre ao rio Liffey, que atravessa a cidade de Dublin, ela simultaneamente chega à sua foz, dissolvendo-se na ambígua figura paterna-conjugal do oceano. Anna Livia aqui é rio e mãe, chegando à sua foz; Anna Livia aqui é filha e água que se fará nuvem, encetando o recomeço. O trecho se encerra em suspenso para que a leitura se retome na primeira página do livro, que se abre em minúscula.

How? How you said how you'd give me the keys of meheart. And we'd be married till delth to uspart. And though devdo espart. O mine! Only, no, now it's me who's got to give. Asduv herself div. Inn this linn. And can it be it's nnowfforvell?Illas! I wisht I had better glances to peer to you through this baylight's growing. But you're changing, acoolsha, you're changingfrom me, I can feel. Or is it me is? I'm getting mixed. Brighteningup and tightening down. Yes, you're changing, sonhusband, andyou're turning, I can feel you, for a daughterwife from the hillsagain. Imlamaya. And she is coming. Swimming in 206 my hindmoist.Diveltaking on me tail. Just a whisk brisk sly spryspink spanksprint of a thing theresomere, saultering. Saltarella come to herown. I pity your oldself I was used to. Now a younger's there.Try not to part! Be happy, dear ones! May I be wrong! For she'llbe sweet for you as I was sweet when I came down out of memother. My great blue bedroom, the air so quiet, scarce a cloud.In peace and silence. I could have stayed up there for always only.It's something fails us. First we feel. Then we fall. And let her rainnow if she likes. Gently or strongly as she likes. Anyway let herrain for my time is come. I done me best when I was let. Thinking always if I go all goes. A hundred cares, a tithe of troubles andis there one who understands me? One in a thousand of years ofthe nights? All me life I have been lived among them but nowthey are becoming lothed to me. And I am lothing their littlewarm tricks. And lothing their mean cosy turns. And all thegreedy gushes out through their small souls. And all the lazyleaks down over their brash bodies. How small it's all! And meletting on to meself always. And lilting on all the time. I thoughtyou were all glittering with the noblest of carriage. You're only

a bumpkin. I thought you the great in all things, in guilt and inglory. You're but a puny. Home! My people were not their sortout beyond there so far as I can. For all the bold and bad andbleary they are blamed, the seahags. No! Nor for all our wilddances in all their wild din. I can seen meself among them, allaniuvia pulchrabelled. How she was handsome, the wild Amazia,when she would seize to my other breast! And what is she weird,haughty Niluna, 
that she will snatch from my ownest hair! For'tis they are the stormies. Ho hang! Hang ho! And the clash ofour cries till we spring to be free. Auravoles, they says, never heedof your name! But I'm loothing them that's here and all I lothe.Loonely in me loneness. For all their faults. I am passing out. Obitter ending! I'll slip away before they're up. They'll never see.Nor know. Nor miss me. And it's old and old it's sad and old it'ssad and weary I go back to you, my cold father, my cold madfather, my cold mad feary father, till the near sight of the meresize of him, the moyles and moyles of it, moananoaning, makes meseasilt saltsick and I rush, my only, into your arms. I see themrising! Save me from those therrble prongs! Two more. Onetwomoremens more. So. Avelaval. My leaves have drifted from me.All. But one clings still. I'll bear it on me. To remind me of. Lff!So soft this morning, ours. Yes. Carry me along, taddy, like youdone through the toyfair! If I seen him bearing down on me nowunder whitespread wings like he'd come from Arkangels, I sinkI'd die down over his feet, humbly dumbly, only to washup. Yes,tid. There's where. First. We pass through grass behush the bushto. Whish! A gull. Gulls. Far calls. Coming,far! End here. Usthen. Finn, again! Take. Bussoftlhee, mememormee! Till thousendsthee. Lps. The keys to. Given! A way a lone a last a loved along the

\section{PARIS}

1922-1939

Como? Como disseste que me dava-las chaves desse meu coração. E a gente casava até que amorfo nu separe. Embora amarte em nós se pare. Ameu! Mas, não, que agora eu quem hei cedar. Qual diabolim cedia. Neste oneste. E pode que ora ceja então ahdeus? Undó. Quis hera ter melhores rechances de expiar-te sobaluz que sobeja na baía. Mas tu mudas, amaré, tu mudasde mim, já percebo. Ou sou eu que? Eu me misto. Incendendo sem cedente. Sim, tu mudas, maridofilho, e tu viras, te percebo, por uma esposafilha de nova dos montes. Imlamaya. Evenhela. Nadando em pós amém. Mengulhando a-trais em mim. Mera felpa de farta não farta dum jato, astuto fato, que arrosa e arrufa tudo alenhures, saltedando. Saltarella assumida. Tenho pena do teu eu que um dia eu soube. Agora é lá outra nova. Tente não se parar! Sejam felizes, amados! Que seja erromeu! Pois ela te há de ser soce como fui doce eu quando descendi de minha amadre. Meu grande quarto azul, ar tão silente, rara a rala nuvem. Empaz em si lente. 
Podia ter ficado tão alta por sempre somente. É algo nos falha. Primeiro sentir. Pois cair. Ela que chova ora então, se prefere. Doce ou forte, qual prefira. Enfim, que ela chova pois chegou minha ora. Fiz o que deu quando deu de fazer. Pensando sempre que se vou vai-se tudo. Cem curas, um cento cuidados e ninguém que me entenda? Um em milhar de anos denoites? Por toda minha vida fui vivida adentre eles mas agora eles em mim se retornam repulsam. Repulso eu também suas mornas manobras pequenas. Repulso seus reles retornos calentes. E todos vorazes vórtices de suas meras alminhas. E todos lentos vazamentos desses corpos rudes. Nonada esse tudo! E eu ali emimesmando o tempo inteiro. E cantante o tempo inteiro. Achava que em ti se achasse o mais alto dos portes. Se és penas campônio. Achava fôsses grande em coisas todas, de culpas, triunfos. Se és menos que anão. Lar! Meu povo não era o que fosse lá longe até onde eu consiga. Por mais que de vis e de más e de fozes sejam tidas, se areias. Não! Não por todas nossas danças loucas em seu louco cantar. Me posso ver-me a entrelas, allaniuvia pulcrabelada. Como era bela, a douda Amazia, quando me tomava um outro seio! E quanto é doutra, altiva Niluna, que retoma do mais próprio meu cabelo! Por isso são elas procelas. Ei vai! Oi vem! E o estrondo desse estrídulo grito até que saltemos liberdadas. Auravoles, dizem eles, nem não pensem nosso nome! Mas repulso-me neles de cá e de cada que pulsa. Sozinha em minha só zinhez. Por culpas deles. Vou com sumindo. Ah fim sem findo! Hei de excapar antes que seergam. Jamais verão. Nem saberão. Nem ter lamentos. E é velha e velha é dolorida e velha é dolorida e fatigada que retorno a ti, meu gelho pai, meu gelho e doidorido pai, meu gelho doidorido e medrontado pai, até que o mero aporte do belo porte dele, demilhas e milhas de ele, gemenente, me faça concha consalgada e que me elance, ó todo meu, nos braços teus. Vejo que sobem! Salva-me de horrendas lanças! Dois mais. Mais um-dois seareios. Assim. Avelaval. Minhas folhas de mim navegaram. Todas. Prende-se uma se apenas. Guardá-la comigo. Para evocar-me de. Lff! Tão doce a manhã, essa nossa. Sim. Me enleva-me, pais, como no par que um dia! Ouvisse agora cadente sobre mim sob asas excãcaradas como quem viesse de Arkangels, subpeito que morrera por cima em seus pés, humildomilde, empura douração. Sim, tid. Eis onde. Primeiro. Roçamos a relva rente ao rés de arbustos rumo. Cai-la! Evola. Gaivola. Longes vozes. Vou indo, meu paz! Fim cá. Nós lá. Finn, alguém! Toma. Masquedoquejá, memimaismim! Té que miles de ti. Lps. As chaves de. Tidas! A via a sola a fim a flora a vinda ao

\section{PARIS}

1922-1939 


\section{Sobre o tradutor}

Caetano Waldrigues Galindo é professor do curso de Letras da UFPR desde 1998. Como tradutor, já escreveu em português mais de cinquenta livros de outras pessoas. Boa parte de seu trabalho na Academia e na tradução literária se dedica à obra de James Joyce. Dele, já traduziu Dublinenses, Um retrato do artista quando jovem, Finn's Hotel, Giacomo Joyce e Ulysses, livro que mereceu também um estudo publicado como Sim, eu digo sim: uma visita guiada ao Ulysses de James Joyce. Neste momento está concluindo a tradução do teatro e da poesia de Joyce, e vem lidando há anos com um projeto de tradução do Finnegans Wake, última peça faltante da obra Joyceana.

\section{BIBLIOGRAFIA}

BRITTO, Paulo Henriques. A tradução literária. Rio de Janeiro: Civilização Brasileira, 2012.

CAMPOS, Augusto de \& Campos, Haroldo de. Panaroma do Finnegans Wake. São Paulo: Perspectiva, 1962.

ECO, Umberto. Quase a coisa coisa. Rio de Janeiro: Record, 2000.

JOYCE, James. Finnegans Wake. Nova York: Penguin Books, 2005.

JOYCE, James. Finnicius Revém (trad. Donaldo SCHÜLER). São Paulo: Ateliê Editorial, 2001-2003.

\footnotetext{
* Caetano Waldrigues GALINDO - Graduado em Letras (1997) pela Universidade Federal do Paraná. Mestre em Letras (2000) pela mesma instituição. Doutor em Linguística (2006) pela Universidade de São Paulo. Realizou pesquisa pós-doutoral (2010) na Pontifícia Universidade Católica do Rio de Janeiro. Professor associado na Universidade Federal do Paraná. Bolsista de Produtividade em Pesquisa do CNPq - Nível 2. Universidade Federal do Paraná, Setor de Ciências Humanas Letras e Artes, Departamento de Linguística Letras Clássicas e Vernáculas. Curitiba, Paraná, Brasil.

Currículo acadêmico: http://lattes.cnpq.br/5561930908519759

ORCID: https://orcid.org/0000-0002-0437-1664

E-mail: cwgalindo@gmail.com
} 